\title{
Occurrence and level of emerging organic contaminant in fish and mollusk from Klang River estuary, Malaysia and assessment on human health risk
}

\begin{abstract}
The occurrence, level, and distribution of multiclass emerging organic contaminants (EOCs) in fish and mollusks from the Klang River estuary were examined. The targeted EOCs for this assessment were phenolic endocrine disrupting compounds (bisphenol A, 4-OP, and 4-NP), organophosphorous pesticides (quinalphos, chlorpyrifos, and diazinon), estrogenic hormones (E2, E1, and EE2), and pharmaceutically active chemicals (primidone, sulfamethoxazole, dexamethasone, diclofenac, amoxicillin, progesterone, and testosterone). Results from this study showed that the prevalent contamination of the Klang River estuary by EOCs with diclofenac, bisphenol A, progesterone, and amoxicillin were predominantly detected in fish and mollusks. Among the EOCs, diclofenac and progesterone had the highest concentrations in fish and mollusk samples, respectively. The concentrations of diclofenac and progesterone in fish and mollusk samples range from $1.42 \mathrm{ng} / \mathrm{g}$ to $10.76 \mathrm{ng} / \mathrm{g}$ and from $0.73 \mathrm{ng} / \mathrm{g}$ to $9.57 \mathrm{ng} / \mathrm{g}$, respectively. Bisphenol A should also be highlighted because of its significant presence in both fish and mollusks. The concentration of bisphenol A in both matrices range from $0.92 \mathrm{ng} / \mathrm{g}$ to $5.79 \mathrm{ng} / \mathrm{g}$. The calculated hazard quotient (HQ) for diclofenac, bisphenol A, and progesterone without consideration to their degradation byproduct were less than one, thus suggesting that the consumption of fish and mollusks from the Klang River estuary will unlikely pose any health risk to consumers on the basis of the current assessment. Nonetheless, this preliminary result is an important finding for pollution studies in Malaysian tropical coastal ecosystems, particularly for organic micropollutant EOCs, and can serve as a baseline database for future reference.
\end{abstract}

Keyword: Emerging organic contaminant; Fish; Mollusk; Health risk assessment; Klang river estuary; Malaysia 